\title{
Mechanisms of circulatory and intestinal barrier dysfunction during whole body hyperthermia
}

\author{
DAVID M. HALL, ${ }^{1}$ GARRY R. BUETTNER,${ }^{2}$ LARRY W. OBERLEY, ${ }^{2}$ \\ LINJING XU, ${ }^{1}$ RONALD D. MATTHES, ${ }^{1}$ AND CARL V. GISOLFI ${ }^{1 \dagger}$ \\ ${ }^{1}$ Department of Exercise Science and ${ }^{2}$ Free Radical and Radiation \\ Biology Program, University of Iowa, Iowa City, Iowa 52242
}

Received 4 April 2000; accepted in final form 23 August 2000

Hall, David M., Garry R. Buettner, Larry W. Oberley, Linjing Xu, Ronald D. Matthes, and Carl V. Gisolfi. Mechanisms of circulatory and intestinal barrier dysfunction during whole body hyperthermia. Am J Physiol Heart Circ Physiol 280: H509-H521, 2001.-This work tested the hypotheses that splanchnic oxidant generation is important in determining heat tolerance and that inappropriate $\cdot \mathrm{NO}$ production may be involved in circulatory dysfunction with heat stroke. We monitored colonic temperature $\left(\mathrm{T}_{\mathrm{c}}\right)$, heart rate, mean arterial pressure, and splanchnic blood flow (SBF) in anesthetized rats exposed to $40^{\circ} \mathrm{C}$ ambient temperature. Heating rate, heating time, and thermal load determined heat tolerance. Portal blood was regularly collected for determination of radical and endotoxin content. Elevating $\mathrm{T}_{\mathrm{c}}$ from 37 to $41.5^{\circ} \mathrm{C}$ reduced SBF by $40 \%$ and stimulated production of the radicals ceruloplasmin, semiquinone, and penta-coordinate iron(II) nitrosyl-heme (heme-·NO). Portal endotoxin concentration rose from 28 to $59 \mathrm{pg} / \mathrm{ml}(P<0.05)$. Compared with heat stress alone, heat plus treatment with the nitric oxide synthase (NOS) antagonist $N^{\omega}$-nitro-L-arginine methyl ester (L-NAME) dose dependently depressed heme--NO production and increased ceruloplasmin and semiquinone levels. L-NAME also significantly reduced lowered SBF, increased portal endotoxin concentration, and reduced heat tolerance $(P<0.05)$. The NOS II and diamine oxidase antagonist aminoguanidine, the superoxide anion scavenger superoxide dismutase, and the xanthine oxidase antagonist allopurinol slowed the rates of heme- NO production, decreased ceruloplasmin and semiquinone levels, and preserved SBF. However, only aminoguanidine and allopurinol improved heat tolerance, and only allpourinol eliminated the rise in portal endotoxin content. We conclude that hyperthermia stimulates xanthine oxidase production of reactive oxygen species that activate metals and limit heat tolerance by promoting circulatory and intestinal barrier dysfunction. In addition, intact NOS activity is required for normal stress tolerance, whereas overproduction of $\cdot \mathrm{NO}$ may contribute to the nonprogrammed splanchnic dilation that precedes vascular collapse with heat stroke.

oxidative stress; nitrosative stress; free radicals; ischemia; heat stroke; electron paramagnetic resonance; endotoxemia

HEAT STROKE IS THE MOST CATASTROPHIC FORM of debilitating illness resulting from environmental heat stress.

\footnotetext{
$\dagger$ Deceased 3 June 2000.

Address for reprint requests and other correspondence: D. M. Hall, Dept. of Exercise Science, Field House, Univ. of Iowa, Iowa City, IA 52242 (E-mail: dmhall@kirkwood.cc.ia.us).
}

Described clinically as either classical (nonexertional) or exertional in nature, heat stroke is a systemic disorder that is characterized by multiorgan injury, severe hypotension, and multisystem organ failure with evidence of multiorgan involvement in precipitating cardiovascular shock $(26,43)$. The etiology of shock with heat stroke remains unclear, but work from Kregel et al. (28) has shown that the initial decline in peripheral resistance occurs within the splanchnic vascular bed and may precipitate the systemic hypotension that is characteristic of heat illness.

In the present study, we tested the hypotheses that splanchnic oxidant generation is an important determinant of heat tolerance and that inappropriate nitric oxide $(\cdot \mathrm{NO})$ production is involved in splanchnic vascular dysfunction with heat stroke. We developed these hypotheses based on previous work from our laboratory (18) demonstrating that hyperthermia stimulates splanchnic production of $\cdot \mathrm{NO}$ and biomarkers of cellular oxidative stress.

With the use of electron paramagnetic resonance (EPR) spectroscopy to directly detect radicals in vivo (18), we observed that hyperthermia progressively increased portal venous content of the following: semiquinone radical, a biomarker of mitochondrial reductive stress (52); ceruloplasmin, an acute phase antioxidant protein that acts to reduce metal-catalyzed oxidant production (29); and penta-coordinate iron(II) nitrosyl-heme (heme--NO) (27). The respective characteristics of these radicals suggest that heat stress stimulates $\cdot \mathrm{NO}$ and reactive oxygen species (ROS) production within splanchnic viscera leading to transition metal activation and cellular oxidative stress. Indeed, our group (19) and others $(36,44)$ have proposed that metal-catalyzed oxidative stress is involved in hyperthermia-related pathology.

The purpose of the present study was to investigate mechanisms of $\cdot \mathrm{NO}$ and ROS production in vivo during environmental heat stress. Figure 1 details a working model that we propose for the etiology of heat illness. We (17) have previously shown that hyperthermia produces cellular hypoxia and metabolic stress within the

\footnotetext{
The costs of publication of this article were defrayed in part by the payment of page charges. The article must therefore be hereby marked "advertisement" in accordance with 18 U.S.C. Section 1734 solely to indicate this fact.
} 


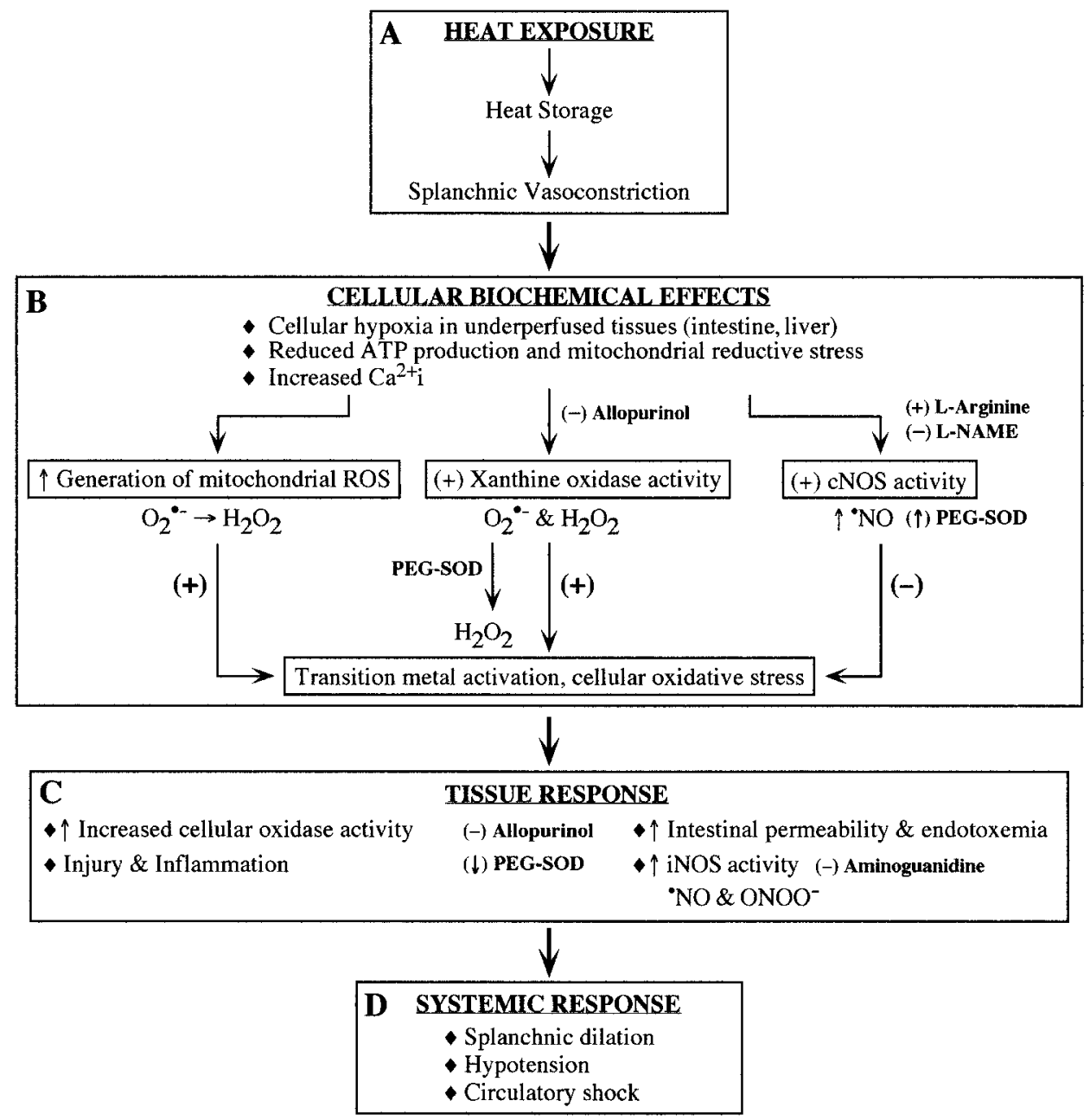

Fig. 1. An overview of our hypothesis of how heat stress leads to multiorgan injury and circulatory dysfunction. $A$ : at the whole organism level, heat stress stimulates metabolism and progressively reduces blood flow to critical splanchnic tissues (the intestine and liver). $B$ : increased metabolic demand coupled with reduced splanchnic blood flow (SBF) generates cellular hypoxia, compromises cellular energy production, and produces derangements in intracellular $\mathrm{Ca}^{2+}\left(\mathrm{Ca}_{\mathrm{i}}^{2+}\right)$ homeostasis. Loss of $\mathrm{Ca}^{2+}$ control increases mitochondrial reactive oxygen species (ROS) production and stimulates cellular oxidase and $\mathrm{Ca}^{2+}$-dependent nitric oxide (NO) synthase (NOS) enzymatic activities. Stimulating mitochondrial ROS production and oxidase activity increases cellular production of $\mathrm{O}_{2}^{-} \cdot$ and $\mathrm{H}_{2} \mathrm{O}_{2} . \mathrm{O}_{2}^{-}$. can activate transition metals, thereby increasing metal-catalyzed cellular oxidative stress. The increased flux of $\cdot \mathrm{NO}$ produced by $\mathrm{Ca}^{2+}$-dependent NOS is protective through its cell regulatory and antioxidant actions. $C$ : as heat stress continues, hypoxic cells export oxidases into the extracellular space, where metalcatalyzed oxidative stress can produce multifocal cellular injury and inflammation. Damage to the intestine increases intestinal permeability to endotoxins, contributing to local inflammation and inducible NOS (iNOS) activation. The large increase in $\cdot \mathrm{NO}$ flux from iNOS promotes reactive nitrogen species (RNS) generation. $D$ : this inappropriate production of ROS and RNS leads to "nonprogrammed" splanchnic dilation, systemic hypotension, and circulatory shock. PEG-SOD, polyethylene glycol-conjugated superoxide dismutase; cNOS, constitutive NOS; L-NAME, $N^{\omega}$-nitro-L-arginine methyl ester.

liver and intestine. We propose that subsequent cellular biochemical events secondary to hypoxia (e.g., increased cytosolic $\mathrm{Ca}^{2+}$ ) promote mitochondrial ROS production and stimulate cellular oxidase and constitutive nitric oxide synthase (NOS) I and III enzymatic activities (Fig. 1B). We further propose that constituitive synthesis of $\cdot \mathrm{NO}$ is protective, buffering the rise in splanchnic vasoconstrictor activity (14) and cellular oxidative stress. If heat stress continues (Fig. 1C), intestinal barrier function may be compromised, increasing translocation of gut contents into the splanchnic circulation where endotoxins and local inflamma- tory mediators such as cytokines (7) would upregulate NOS II enzymatic activity. The higher cellular flux of -NO produced by NOS II would promote reactive nitrogen species generation and nonprogrammed splanchnic dilation. Unresolved questions in this model include identification of the principle source(s) of ROS and $\cdot \mathrm{NO}$ during heat stress.

To test these ideas, in vivo experiments were designed to examine the effects of 1) antagonizing NOS enzymatic activity, 2) increasing NOS substrate availability, 3) limiting superoxide anion bioavailability with polyethyleneglycol (PEG)-conjugated copper and 
zinc-containing superoxide dismutase (PEG-SOD), and 4) antagonizing the heat-sensitive ROS-producing enzyme xanthine oxidase with allopurinol.

\section{MATERIALS AND METHODS}

\section{Animals}

Male Sprague-Dawley rats (Harlan, Indianapolis, IN) weighing 300-350 g served as subjects. Rats were purchased in groups of 15 and housed in the University of Iowa Animal Care Facility at an ambient temperature of $22-24^{\circ} \mathrm{C}$ on a 12:12-h light-dark cycle. Animals were handled and familiarized with laboratory procedures for 3-5 days before use as experimental subjects. Food and water were provided ad libitum.

Rats were randomly assigned to the following groups: 1) sham-operated normothermic control $(n=4), 2)$ salinetreated normothermic control $(n=4), 3)$ noninjected hyperthermic control $(n=4), 4)$ saline-treated hyperthermic control $(n=10), 5) N^{\omega}$-nitro-L-argine methyl ester (L-NAME)treated $(25,50$, and $125 \mu \mathrm{M})$ heat exposed $(n=24), 6)$ aminoguanidine-treated $(25$ and $50 \mu \mathrm{M})$ heat exposed $(n=$ 16), 7) L-arginine-treated (100, 200, and $300 \mu \mathrm{M})$ heat exposed $(n=24), 8$ ) PEG-SOD-treated ( 10 and $30 \mathrm{mg} / \mathrm{kg}$ body wt) heat exposed ( $n=16), 9)$ PEG-SOD-treated normothermic control $(n=4)$, and 10) allopurinol-treated (10, 20, and $30 \mathrm{mg} / \mathrm{kg}$ body wt) heat exposed $(n=24)$.

\section{Experimental Design}

Experiments were conducted between 800 and $1300 \mathrm{~h}$. After surgical preparation, anesthetized rats were exposed to $40^{\circ} \mathrm{C}$ ambient temperature $\left(\mathrm{T}_{\mathrm{a}}\right)$ in a temperature-controlled environmental chamber while they received intravenous injections of the designated pharmacological agent. Thermocouples placed around the animal continuously monitored $\mathrm{T}_{\mathrm{a}}$. Preliminary experiments established that enzyme blockade was not maintained for the duration of an experiment if a single bolus injection of a reagent was used. Therefore, rats received injections $(10 \mu \mathrm{l} / 100 \mathrm{~g}$ body wt iv) at time 0 (beginning of heat exposure) and at 15-min intervals until termination of an experiment ( $90 \mathrm{~min})$. Because of its long vascular half-life (41), PEG-SOD was given as two injections within the first 15 min of heating.

Colonic temperature $\left(\mathrm{T}_{\mathrm{c}}\right)$, heating time, mean arterial pressure (MAP), heart rate (HR), and superior mesenteric artery (SMA) blood flow were continually monitored. From these data, thermal load and splanchnic resistance were calculated. Portal venous and femoral artery blood samples were collected for analyses of radical and endotoxin content at four time points: 1) immediately before heat exposure $\left.\left(\mathrm{T}_{\mathrm{c}} \approx 37^{\circ} \mathrm{C}\right), 2\right)$ at $\left.\mathrm{T}_{\mathrm{c}}=41.5^{\circ} \mathrm{C}, 3\right)$ immediately after SMA flow increased, and 4) after MAP fell below $100 \mathrm{mmHg}$. Heat exposure was terminated when MAP fell below $100 \mathrm{mmHg}$. Experiments were terminated when MAP fell below 60 $\mathrm{mmHg}$.

\section{Surgical Preparation}

Animals were anesthetized with pentobarbital sodium (Nembutal; $50 \mathrm{mg} / \mathrm{kg}$ ip), injected with atropine (100 $\mu \mathrm{l})$, and tracheotomized to ensure a patent airway. An incision was made in the inguinal region of the right hindlimb. The femoral artery was isolated for $\sim 1 \mathrm{~cm}$ of its length and fitted with a catheter [polyethylene (PE)-50; Clay Adams, Parsippany, $\mathrm{NJ}$ f filled with heparinized saline $(100 \mathrm{U} / \mathrm{ml})$ to monitor HR and MAP and to sample blood. The leg incision was closed, and a midline laparotomy was performed. The portal vein was isolated $\sim 2 \mathrm{~mm}$ from the liver, and a second catheter for sampling blood and delivering pharmacological agents was placed in the portal vein through a tributary vessel. Tributary vessels were chosen as cannulation sites to avoid impeding portal blood flow. Catheter placement was confirmed at the conclusion of each experiment.

The superior mesenteric artery was next isolated for $\sim 1$ $\mathrm{cm}$ of its length, and a miniaturized Transonic Doppler flow probe was positioned around the vessel to monitor SMA blood flow. The abdominal incision was closed, and a colonic temperature $\left(\mathrm{T}_{\mathrm{c}}\right)$ probe (36-gauge copper-constantan wire in PE100 tubing) was inserted $7-8 \mathrm{~cm}$ past the anal sphincter to monitor $\mathrm{T}_{\mathrm{c}}$.

Rats were allowed to stabilize for $30 \mathrm{~min}$ after surgery. Baseline HR, MAP, and SMA blood flow data were collected for an additional $30 \mathrm{~min}$. During this 60 -min period, $\mathrm{T}_{\mathrm{c}}$ was maintained at $37.0 \pm 0.2^{\circ} \mathrm{C}$ with a heating pad. At the end of the control period, baseline portal venous and femoral artery blood samples were collected, and the $\mathrm{T}_{\mathrm{a}}$ of the environmental chamber was elevated to $40^{\circ} \mathrm{C}$ with a relative humidity of $30 \%$.

\section{Sample Collection and Handling}

Cardiovascular data. MAP was determined by connecting the femoral artery catheter to a Gould P23 ID pressure transducer that electronically averages the pulsatile signal. $\mathrm{HR}$ was determined from the number of electronic pulsations sensed by a cardiotachometer (Beckman Instruments). SMA blood flow was determined using a pulsed Transonics Doppler flowmeter (University of Iowa Bioengineering Resource Facility). MAP, HR, and SMA blood flow were continuously monitored, and the mean value over each 60 -s period was recorded.

Radicals and serum endotoxin. Portal venous and femoral artery blood samples (350 $\mu \mathrm{l}$ each) were collected in sterile, 1 -ml Monoject syringes (2). Whole blood (200 $\mu \mathrm{l})$ was immediately delivered into a quartz EPR tube (inner diameter 3 $\mathrm{mm}$ ) and frozen at $77 \mathrm{~K}$ pending EPR analyses as previously described (18). The remaining $150 \mu \mathrm{l}$ of blood was processed for quantitation of gram-negative bacterial endotoxin concentration per manufacturer's instructions [limulus amebocyte lysate (LAL), quantitative chromogenic LAL, BioWhittaker, Walkersville, MD]. Briefly, cell and serum fractions were isolated by centrifugation in a refrigerated clinical microcentrifuge. The serum was extracted and delivered to pyrogenfree storage tubes (BioWhittaker), diluted 1:10 with pyrogenfree water, and heated for $10 \mathrm{~min}$ at $70^{\circ} \mathrm{C}$ to remove nonspecific LAL inhibitors present in blood products (8). Processed serum was stored at $-80^{\circ} \mathrm{C}$ pending endotoxin assay. Serum from all samples was tested in triplicate. All materials coming into contact with blood or test materials not purchased as pyrogen-free from BioWhittaker were rendered pyrogen-free by heating at $200^{\circ} \mathrm{C}$ for $4 \mathrm{~h}$.

\section{EPR Conditions}

EPR spectra were recorded with a Bruker ESP 300 EPR spectrometer (Bruker Instruments, Karlsruhe, Germany) equipped with an ER035M gaussmeter, an ER4111VT variable-temperature unit, and an EIP-625A microwave-frequency counter. Signal averaging (multiple scans of the same sample) was used to improve the signal-to-noise ratio. Sample volume and geometry were kept constant to allow for comparisons of radical concentration between samples. All spectra were collected at $100 \mathrm{~K}$, with data reported as the normalized average of 20 scans. EPR conditions were the 
following: receiver gain $5.00 \times 10^{5}$, modulation frequency 100 $\mathrm{kHz}$, modulation amplitude 4.0 Gauss $(\mathrm{G})$, microwave frequency $9.43 \mathrm{GHz}$, microwave power $10 \mathrm{~mW}$, and scan rate $6.0 \mathrm{G} / \mathrm{s}$.

\section{Calculations}

Thermal stress was quantified by determining thermal load, a product of $\mathrm{T}_{\mathrm{c}}$ and time spent above $40.4^{\circ} \mathrm{C}(22) . \mathrm{T}_{\mathrm{c}}$ was recorded at 1 -min intervals, and thermal load $\left({ }^{\circ} \mathrm{C} \times \min \right)$ was calculated as the following: the sum of the time interval (in $\min ) \times\left[\left(\mathrm{T}_{\mathrm{c}}\right.\right.$ above $\left.\left.40.4^{\circ} \mathrm{C}-40.4^{\circ} \mathrm{C}\right)\right]$. Heating rate $\left(\right.$ in $\left.{ }^{\circ} \mathrm{C} / \mathrm{min}\right)$ was calculated as the following: (maximum $\mathrm{T}_{\mathrm{c}}$ attained during heat exposure - baseline $\mathrm{T}_{\mathrm{c}}$ )/total heating time (in $\mathrm{min}$ ).

Splanchnic vascular resistance is equal to pressure (in $\mathrm{mmHg}$ ) divided by $\mathrm{SMA}$ flow ( $\mathrm{kHz}$ shift). The percent change in splanchnic vascular resistance was calculated using the following formula: $\left[\left(R_{t}-R_{c}\right) / R_{c}\right] \times 100$, where $R_{c}$ is baseline MAP divided by the mean SMA flow value in the control period and $R_{t}$ equals MAP divided by the SMA flow value in the test period (20).

\section{Statistical Analyses}

Thermal responses, endotoxin values, and cardiovascular data were analyzed by one-way analysis of variance. Groups were categorized according to Tukey's multiple comparisons procedure. Significant differences were identified with Dunnet's test. Differences were considered significant at the $P<$ 0.05 level.

\section{RESULTS}

\section{Normal Heat Stress Responses}

Our initial set of experiments was designed to characterize the typical radical, hemodynamic, and splanchnic endotoxin responses of the heat-stressed rat. To examine splanchnic hemodynamics and splanchnic radical production in parallel, Fig. 2 presents SMA blood flow and portal EPR spectra versus $\mathrm{T}_{\mathrm{c}}$. There were no differences in the responses of noninjected hyperthermic rats and saline-treated hyperthermic an- imals; therefore, data from these two groups were pooled and are referred to as hyperthermic controls.

EPR spectra of portal blood collected before heat stress displayed a weak composite signal, suggesting the presence of multiple radicals. The narrow $\mathrm{g}=2.005$ feature (peak-to-peak line width $\sim 10 \mathrm{G}$ ) represents semiquinone radical (Fig. 2A) (18). The broad deflection at $\mathrm{g}=2.06$, indicative of a transition metal, represents ceruloplasmin (Fig. $2 B$ ) (4).

Elevating $\mathrm{T}_{\mathrm{c}}$ from 37 to $41.5^{\circ} \mathrm{C}$ stimulated a $127 \pm$ $7 \%$ increase in splanchnic resistance (Table 1), a $40 \pm$ $2 \%$ reduction in splanchnic blood flow (SBF) (Fig. 2 and Table 1), and increased circulating ceruloplasmin and semiquinone radical levels (Fig. $2 B$ ). The decline in SBF was nonlinear in nature, with a sharp decrease occurring at $\mathrm{T}_{\mathrm{c}}>40^{\circ} \mathrm{C}$ (Fig. 2). Heart rate and MAP (Fig. 3, control) progressively increased with rising $\mathrm{T}_{\mathrm{c}}$, peaking at $589 \pm 16 \mathrm{beats} / \mathrm{min}$ and $170 \pm 2 \mathrm{mmHg}$, respectively (Table 1 ).

At $\mathrm{T}_{\mathrm{c}}$ of $41.5^{\circ} \mathrm{C}$, we observed the evolution of a triplet EPR signal centered at $\mathrm{g}=2.012$ (splitting constant $\sim 17.5 \mathrm{G}$ ) (Fig. 2, $B$ and $C$ ) that represents heme- $\mathrm{NO}$ (18, 27). EPR evidence of heme- NO was not observed in arterial blood (data not shown), suggesting that this was a local phenomenon within the splanchnic region. Splanchnic resistance fell and SBF rapidly increased at $\mathrm{T}_{\mathrm{c}}$ of $41.8 \pm 0.2^{\circ} \mathrm{C}$. EPR of portal blood collected immediately after the initial rise in $\mathrm{SBF}$ shows a strong heme-·NO signal (Fig. $2 C$ ), suggesting that overproduction of $\cdot \mathrm{NO}$ may contribute to declining splanchnic resistance. Only the ceruloplasmin signal was observed in arterial blood samples (data not shown), again suggesting that the rise in heme- NO levels was a local event within the splanchnic circulation. HR and MAP (Fig. 3, control) declined at $\mathrm{T}_{\mathrm{c}}$ of $42.0 \pm 0.2^{\circ} \mathrm{C}$ 25-7 min after rising SBF. Total heating time for hyperthermic controls was $77 \pm 4 \mathrm{~min}$, and thermal load was $34.4 \pm 3.2^{\circ} \mathrm{C} \times \min ($ Table 1$)$. We interpret
Fig. 2. Heat stress reduces SBF and stimulates production of semiquinone radical, ceruloplasmin, and pentacoordinate iron(II) nitrosyl-heme (heme- $\mathrm{NO}$ ). SBF was progressively reduced as colonic temperature $\left(\mathrm{T}_{\mathrm{c}}\right)$ rose from 38 to $\sim 41.3^{\circ} \mathrm{C}$. Coincident with the reduction in $\mathrm{SBF}$, there occurred an increase in splanchnic levels of ceruloplasmin $(\mathrm{g}=2.06)$ and semiquinone radical $(\mathrm{g}=$ $2.005)$; compare the low temperature $(100 \mathrm{~K})$ electron paramagnetic resonancy (EPR) spectra $A$ and $B$ from portal venous (PV) blood. Just before rising SBF, we observed increased heme--NO levels $\left[\mathrm{g}=2.012 ; a^{\mathrm{N}} \approx 17\right.$ Gauss $(\mathrm{G})](B)$. SBF rapidly increased at $\mathrm{T}_{\mathrm{c}}>41.8^{\circ} \mathrm{C}$ followed $(\sim 5 \mathrm{~min})$ by falling mean arterial pressure (MAP). Note that EPR spectra from portal venous blood samples collected just before and during the rapid rise in $\mathrm{SBF}(B$ and $C$ ) are dominated by heme--NO, consistent with $\cdot \mathrm{NO}$ involvement in declining splanchnic resistance. The presence of an EPR signal from ceruloplasmin suggests that hyperthermia increased transition metal activation, resulting in an adaptive increase in hepatic acute-phase protein release. Error bars represent the means \pm SD from 14 animals. SMA, superior mesenteric artery; $\mathrm{T}_{\mathrm{a}}$, ambient temperature; $a^{\mathrm{N}}$, splitting contant.

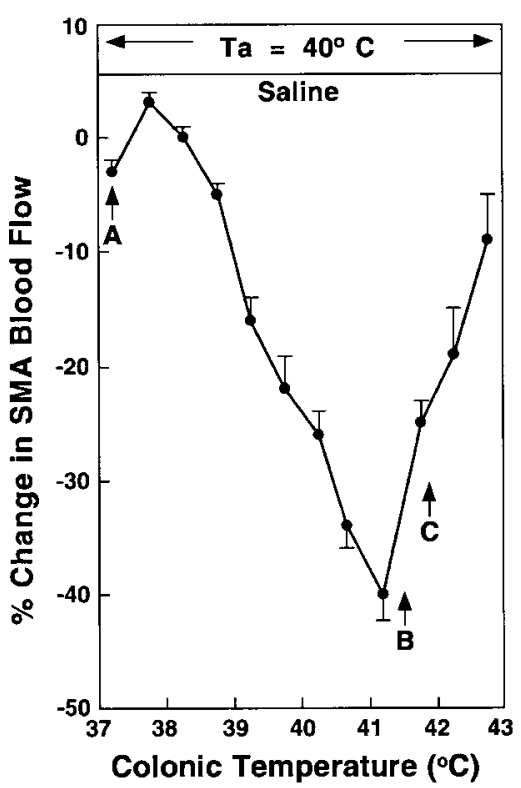

EPR Spectra from PV Blood

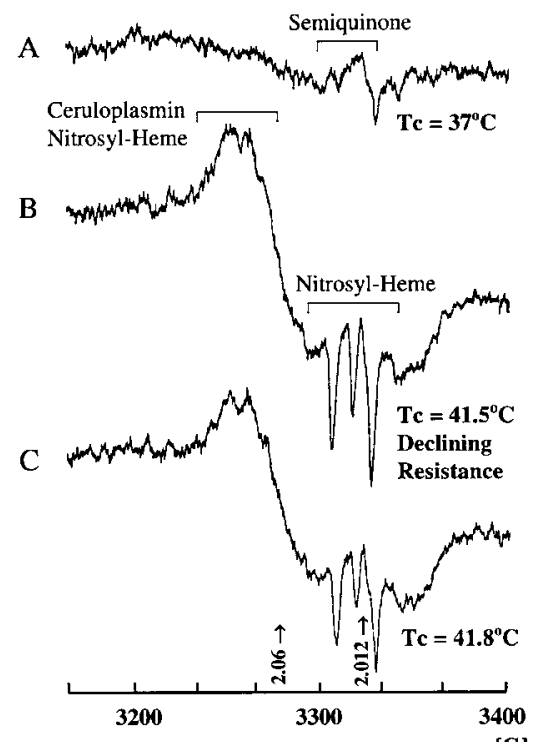


Table 1. Cardiovascular and thermal responses to whole body hyperthermia

\begin{tabular}{|c|c|c|c|c|c|c|c|}
\hline Groups & $\begin{array}{c}\% \Delta \text { SMA } \\
\text { blood flow }\end{array}$ & $\% \Delta \mathrm{R}$ & $\begin{array}{l}\text { MAP, } \\
\text { mmHg }\end{array}$ & HR, beats/min & $\begin{array}{c}\mathrm{TL}, \\
{ }^{\circ} \mathrm{C} \times \min \end{array}$ & HT, min & $\begin{array}{l}\text { Heating Rate, } \\
{ }^{\circ} \mathrm{C} / \mathrm{min}\end{array}$ \\
\hline Control & $-40 \pm 2$ & $127 \pm 7$ & $170 \pm 2$ & $589 \pm 16$ & $34.4 \pm 3.2$ & $77 \pm 4$ & $0.0773 \pm 0.0008$ \\
\hline L-NAME $(25 \mu \mathrm{M})$ & $-37 \pm 5$ & $143 \pm 26$ & $177 \pm 5$ & $592 \pm 12$ & $37 \pm 9.7$ & $85 \pm 3^{*}$ & $0.0622 \pm 0.0007$ \\
\hline L-NAME $(50 \mu \mathrm{M})$ & $-56 \pm 3 *$ & $149 \pm 11$ & $171 \pm 3$ & $541 \pm 11^{*}$ & $26 \pm 4.1$ & $70 \pm 5$ & $0.0814 \pm 0.0006$ \\
\hline L-NAME $(125 \mu \mathrm{M})$ & $-73 \pm 1^{*}$ & $250 \pm 24^{*}$ & $172 \pm 3$ & $464 \pm 4^{*}$ & $11 \pm 5.3^{*}$ & $62 \pm 4^{*}$ & $0.0600 \pm 0.0004$ \\
\hline $\mathrm{AG}(25 \mu \mathrm{M})$ & $-34 \pm 5$ & $132 \pm 8$ & $184 \pm 1 *$ & $675 \pm 9 *$ & $55.6 \pm 2.7^{*}$ & $111 \pm 8^{*}$ & $0.0627 \pm 0.0004$ \\
\hline $\mathrm{AG}(50 \mu \mathrm{M})$ & $-44 \pm 3$ & $155 \pm 9 *$ & $180 \pm 1 *$ & $625 \pm 11$ & $27.2 \pm 3.1^{*}$ & $68 \pm 6$ & $0.0752 \pm 0.0009$ \\
\hline L-Arg $(100 \mu \mathrm{M})$ & $-33 \pm 4$ & $148 \pm 14$ & $177 \pm 2^{*}$ & $658 \pm 6^{*}$ & $27.5 \pm 4$ & $78 \pm 3$ & $0.0684 \pm 0.0005$ \\
\hline L-Arg $(200 \mu \mathrm{M})$ & $-46 \pm 5$ & $180 \pm 26^{*}$ & $173 \pm 3$ & $585 \pm 12$ & $27 \pm 8.6$ & $76 \pm 4$ & $0.0711 \pm 0.0006$ \\
\hline L-Arg $(300 \mu \mathrm{M})$ & $-71 \pm 5^{*}$ & $265 \pm 35^{*}$ & $172 \pm 4$ & $572 \pm 8$ & $36.5 \pm 9.7$ & $83 \pm 3$ & $0.0511 \pm 0.0008$ \\
\hline $\operatorname{SOD}(10 \mathrm{mg} / \mathrm{kg})$ & $-12 \pm 3^{*}$ & $72 \pm 5^{*}$ & $186 \pm 3^{*}$ & $645 \pm 9 *$ & $48.5 \pm 1.8^{*}$ & $80 \pm 4$ & $0.0814 \pm 0.0006$ \\
\hline SOD $(30 \mathrm{mg} / \mathrm{kg})$ & $-7 \pm 6^{*}$ & $50 \pm 10 *$ & $174 \pm 3$ & $670 \pm 8^{*}$ & $43.3 \pm .7 *$ & $82 \pm 3$ & $0.0787 \pm 0.0005$ \\
\hline All $(10 \mathrm{mg} / \mathrm{kg})$ & $-36 \pm 2$ & $154 \pm 8^{*}$ & $188 \pm 3^{*}$ & $677 \pm 23^{*}$ & $47.1 \pm 1.8^{*}$ & $87 \pm 4^{*}$ & $0.0853 \pm 0.0004$ \\
\hline All $(30 \mathrm{mg} / \mathrm{kg})$ & $-40 \pm 3$ & $162 \pm 12^{*}$ & $184 \pm 2 *$ & $637 \pm 24^{*}$ & $45.9 \pm 2.1^{*}$ & $89 \pm 3 *$ & $0.0797 \pm 0.0003$ \\
\hline
\end{tabular}

Data represent peak responses attained during the heating period (means $\pm \mathrm{SD}$ ). \% $\Delta \mathrm{SMA}$, percent change in superior mesentery artery blood flow; \% $\Delta \mathrm{R}$, percent change in splanchnic resistance; MAP, mean arterial pressure; HR, heart rate; TL, thermal load; HT, heating time; L-NAME, $N^{\omega}$-nitro-L-arginine methyl ester; AG, aminoguanidine; L-Arg, L-arginine; SOD, superoxide dismutase; All, allopurinol. * Significantly different from control, $P<0.05$.

these results as evidence that heat stress increases metal activation and $\cdot \mathrm{NO}$ production within splanchnic tissues.

\section{L-NAME}

These experiments tested the hypothesis that globally antagonizing NO synthase (NOS) with L-NAME (37) would lower heme--NO production and prevent splanchnic dilation. However, because of the antioxidant actions of $\cdot \mathrm{NO}(21,25,50,51)$, we further hypothesized that antagonizing NOS would enhance cellular oxidative stress and lower heat tolerance.

Compared with hyperthermic controls, treatment with $25 \mu \mathrm{M}$ L-NAME reduced SBF by $>20 \%$ and rapidly increased ceruloplasmin and semiquinone radical levels (Fig. 4, $B$ vs. $A$ ). Low-dose L-NAME also reduced, but did not eliminate, splanchnic heme- $\mathrm{NO}$ production (Fig. $4 C$ vs. Fig. $2 C$ ) and marginally elevated the $\mathrm{T}_{\mathrm{c}}$ at which splanchnic dilation was observed (Fig. 4). The net effect of $25 \mu \mathrm{M}$ L-NAME treatment was a decreased rate of splanchnic heme--NO production and maintenance of splanchnic constriction but an increase in biomarkers of oxidative stress. Peak MAP and heat tolerance, as determined by total heating time and thermal load, were not altered (Table 1).

In contrast, EPR-detectable heme--NO was not observed with higher concentrations of L-NAME (Fig. 5, $B$ and $C$ ). Compared with hyperthermic controls, both 50 and $125 \mu \mathrm{M}$ L-NAME significantly increased resistance (Table 1) and reduced SBF (Fig. 5). Both 50 and 125 $\mu \mathrm{M}$ L-NAME increased ceruloplasmin and semiquinone radical levels (Fig. $5 B$ vs. Fig. $4 B$ ), suggesting that antagonizing NOS increased cellular oxidative stress and metal activation. L-NAME treatment also eliminated the rise in $\mathrm{SBF}$ at high $\mathrm{T}_{\mathrm{c}}$ (Fig. 5), suggesting that activation of NOS contributes to the observed splanchnic dilation. In addition, 50 and $125 \mu \mathrm{M}$ LNAME dose dependently reduced peak HR (Fig. 3 and Table 1) and lowered heat tolerance (Table 1).

\section{Aminoguanidine}

These experiments were designed to test the tenet that NOS II activation may be involved in splanchnic dilation during heat stress. We hypothesized that aminoguanidine treatment would slow the rate of heme-NO accumulation, delay splanchnic dilation, and improve heat tolerance. We chose concentrations of 25 and $50 \mu \mathrm{M}$ aminoguanidine based on the work of Grisham et al. (16) and Corbett et al. (6), who demonstrated in vivo the relative specificity of aminoguanidine for NOS II over NOS I and III. Vascular radical profile was similar between 25 and $50 \mu \mathrm{M}$ aminoguanidine treatments; therefore, EPR spectra from the 25 $\mu \mathrm{M}$-treated group are presented.

Compared with hyperthermic controls, aminoguanidine treatment increased ceruloplasmin and semiquinone radical levels and significantly increased the magnitude of rise in $\mathrm{T}_{\mathrm{c}}$ required to produce portal heme- $\mathrm{NO}$ accretion and splanchnic dilation (42.7 vs. $41.5^{\circ} \mathrm{C}$ for hyperthermic controls, $P<0.05$ ) (Fig. 6 vs. Fig. 2). Aminoguanidine (25 $\mu \mathrm{M})$ also shifted the blood flow curve rightward (Fig. 6), significantly slowing the rate of reduction in SBF. The net effect was a slower rate of splanchnic heme-NO production (Fig. 6, $B$ and $C$ ) and maintenance of splanchnic constriction but a rise in the levels of biomarkers of cellular oxidative stress. Aminoguanidine $(25 \mu \mathrm{M})$ also reduced the magnitude of rise in SBF on splanchnic dilation (Fig. 6), increased peak MAP and HR, and improved heat tolerance more than any other treatment (Table 1). In contrast, $50 \mu \mathrm{M}$ aminoguanidine significantly reduced heat tolerance (Table 1).

\section{L-Arginine}

L-Arginine is a critical substrate for NOS. These experiments tested the hypothesis that L-arginine supplementation would increase hyperthermia-induced -NO production, blunt the rise in splanchnic resistance, and preserve SBF. Contrary to our hypothesis, L-argi- 
Fig. 3. NOS appears to be involved in heart rate and MAP responses during heat stress. Concentrations of L-NAME $>25 \mu \mathrm{M}$ significantly lowered the peak heart rate (HR) (A) achieved during heat stress and significantly reduced heat tolerance. NOS antagonist L-NAME $(25,50$, and $125 \mu \mathrm{M} ; n=8 \mathrm{rats} /$ group) dose dependently increased MAP $(B)$ during the early stages of heat stress. Only $100 \mu \mathrm{M}$ L-arginine (L-ARG) increased peak HR (C) achieved during heat stress, whereas concentrations greater than $100 \mu \mathrm{M}$ had little effect on HR or MAP $(D)$, but significantly reduced heat tolerance $(n=$ $8 \mathrm{rats} /$ group). The iNOS antagonist aminoguanidine (AG) $(25$ and $50 \mu \mathrm{M} ; n=8$ rats/group) increased peak $\mathrm{HR}(E)$ attained during heat stress, but only $25 \mu \mathrm{M}$ aminoguanidine significantly increased both HR and MAP $(F)$ and significantly increased heat tolerance. *Significantly different from control, $P<$ 0.05 . Rats received injections $(10 \mu \mathrm{l} / 100$ $\mathrm{g}$ body wt iv) at time 0 (beginning of heat exposure) and at 15-min intervals until termination of an experiment. bpm, Beats/min.
A
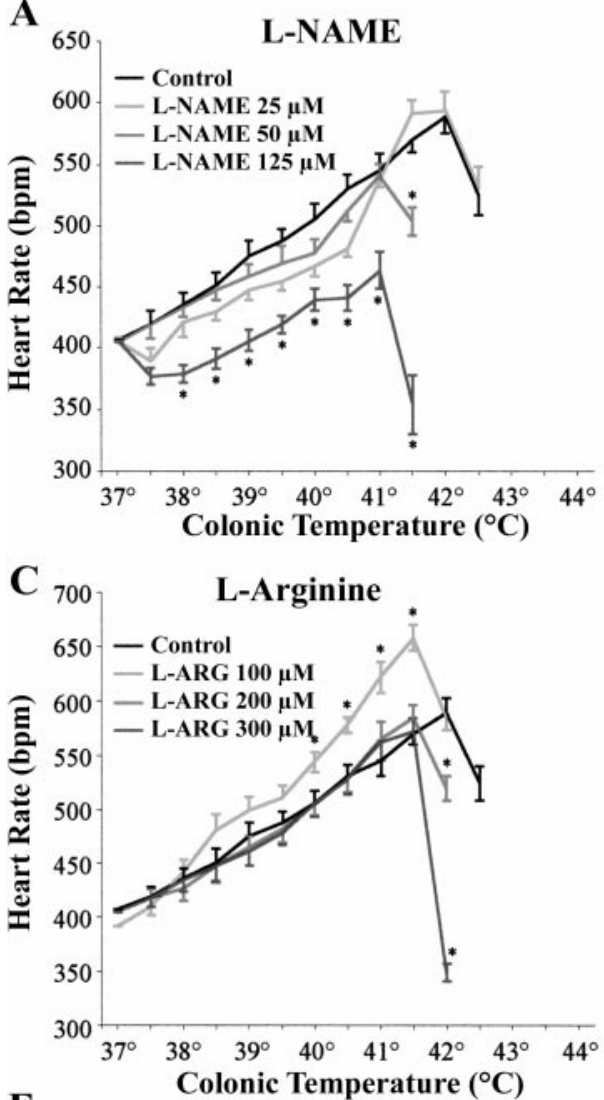

E

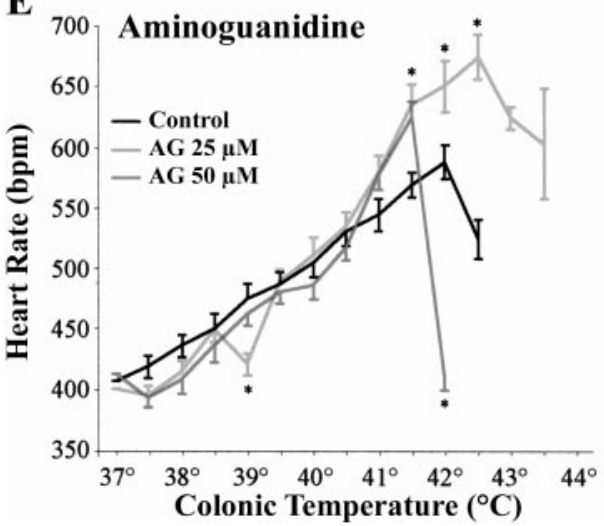

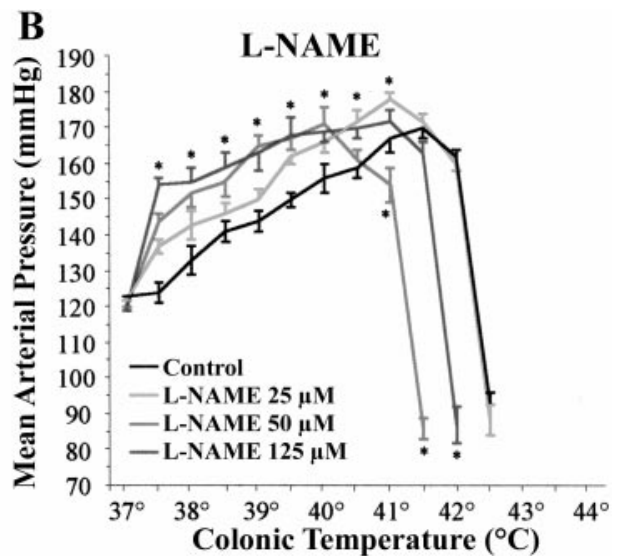
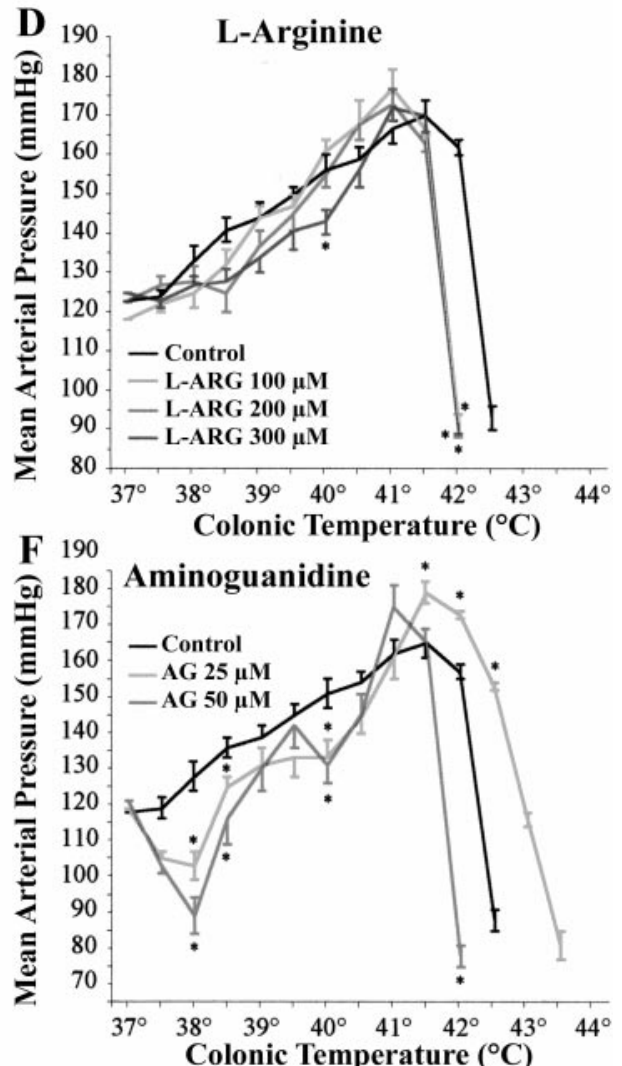

nine dose dependently increased splanchnic resistance and MAP and lowered SBF (Table 1); events that occurred independent of alterations in splanchnic heme- $\mathrm{NO}$ production (data not shown). We speculate that the increase in resistance and MAP may be due to arginine-stimulated splanchnic vasoconstrictor release (32).

\section{PEG-SOD}

SOD scavenges $\mathrm{O}_{2}^{-}$, directly blocking $\mathrm{O}_{2}^{-} \cdot$-mediated chemistry and indirectly increasing the bioavailability of $\cdot$ NO. PEG-SOD is a large molecule with a vascular half-life of 18-24 h (41). With the use of PEG-CuZnSOD, these experiments tested the hypothesis that heat stress stimulates $\mathrm{O}_{2}^{-} \cdot$ production, which is involved in regulating splanchnic hemodynamics and in cellular events leading to semiquinone radical production and ceruloplasmin release. Vascular radical profile was similar between 10 and $30 \mathrm{mg} / \mathrm{kg}$ PEG-SOD treatments; therefore, spectra from $10 \mathrm{mg} / \mathrm{kg}$-treated animals are presented.

Treatment with PEG-SOD markedly reduced splanchnic constriction (Table 1) and maintained SBF at or near euthermic control levels throughout heat exposure (Fig. 7). PEG-SOD also blunted the rise in ceruloplasmin and semiquinone radical levels (Fig. 7, $B$ vs. $A$ ) and significantly increased the magnitude of rise in $\mathrm{T}_{c}$ required to elicit heme- $\mathrm{NO}$ accumulation and splanchnic dilation $\left(42.5\right.$ vs. $41.5^{\circ} \mathrm{C}$ for hyperthermic controls, $P<0.05$ ) (Fig. 7 vs. Fig. 2). Once resistance declined in this group, SBF rose to $44 \pm 8 \%$ above euthermic baseline. Peak HR and MAP were signifi- 


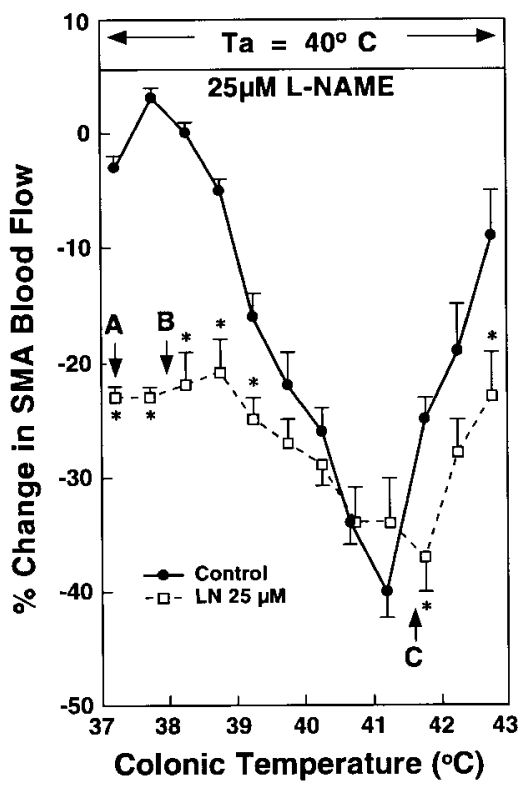

EPR Spectra from PV Blood

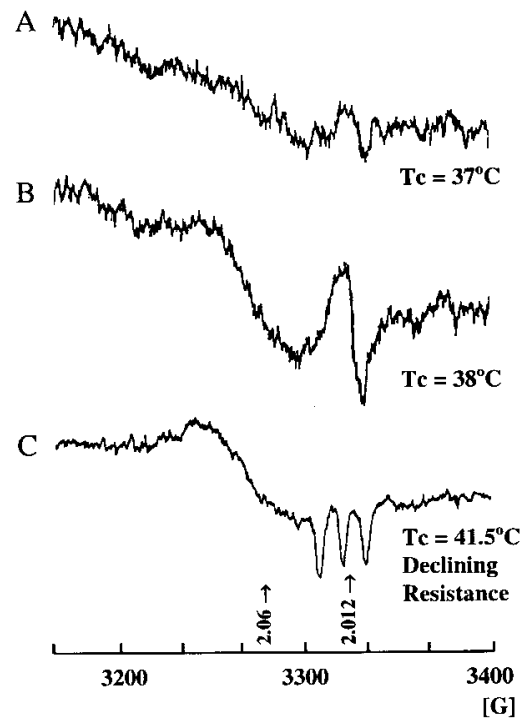

Fig. 4. The influence of the NOS antagonist L-NAME (LN) on vascular responses during heat stress. Compared with hyperthermic controls, treatment with the NOS antagonist L-NAME ( $25 \mu \mathrm{M} ; n=8)$ significantly reduced $\mathrm{SBF}$ at $\mathrm{T}_{\mathrm{c}} \leq 39.0^{\circ} \mathrm{C}$ and rapidly increased semiquinone radical and ceruloplasmin formation $(A$ vs. $B$, respectively), suggesting that blocking NOS activity increased metal activation and cellular oxidative stress. L-NAME treatment also blunted, but did not eliminate, the rise in heme-- $\mathrm{NO}$ and delayed splanchnic dilation until $\mathrm{T}_{\mathrm{c}} \sim 42^{\circ} \mathrm{C}$. Note that a strong heme--NO signal was evident immediately before the rapid rise in $\mathrm{SBF}$ at $41.8^{\circ} \mathrm{C}$, consistent with $\cdot \mathrm{NO}$ involvement in splanchnic dilation. *Significantly different from control, $P<0.05$. cantly increased (Fig. 8), and HR was preserved at or near peak levels until termination of an experiment $\left(\mathrm{T}_{\mathrm{c}}=43.3 \pm 0.3^{\circ} \mathrm{C}\right)($ Fig. 8).

Both 10 and $30 \mathrm{mg} / \mathrm{kg}$ PEG-SOD significantly increased thermal load (Table 1). However, neither dose increased total heating time, and both the rate of rise in $\mathrm{T}_{\mathrm{c}}$ and the maximum $\mathrm{T}_{\mathrm{c}}$ attained before shock were greater than that of hyperthermic controls (Table 1), suggesting that lowering splanchnic constriction negatively impacted heat-dissipating capacity in this group.

\section{Allopurinol}

Allopurinol is a competitive antagonist of xanthine oxidase, an enzyme that directly produces $\mathrm{O}_{2}^{-} \cdot$ and hydrogen peroxide $\left(\mathrm{H}_{2} \mathrm{O}_{2}\right)$. The intestine and liver are rich in xanthine oxidase protein, which is localized primarily to hepatic sinusoidal endothelial cells and intestinal epithelial cells (23). These experiments tested the hypothesis that heat stress can stimulate xanthine oxidase production of ROS that influence splanchnic hemodynamics and participate in cellular events leading to semiquinone radical production and ceruloplasmin release. Vascular radical profile was similar between 10 and $30 \mathrm{mg} / \mathrm{kg}$ allopurinol treatments; therefore, spectra from $10 \mathrm{mg} / \mathrm{kg}$-treated animals are presented.

Treatment with allopurinol markedly decreased splanchnic semiquinone radical and ceruloplasmin levels (Fig. 9). EPR spectra of portal blood collected at $41.5^{\circ} \mathrm{C}$ (Fig. 9B) and $42.7^{\circ} \mathrm{C}$ (Fig. 9C) showed little change in ceruloplasmin or semiquinone radical concentrations from $37^{\circ} \mathrm{C}$ levels. As with PEG-SOD, allopurinol also
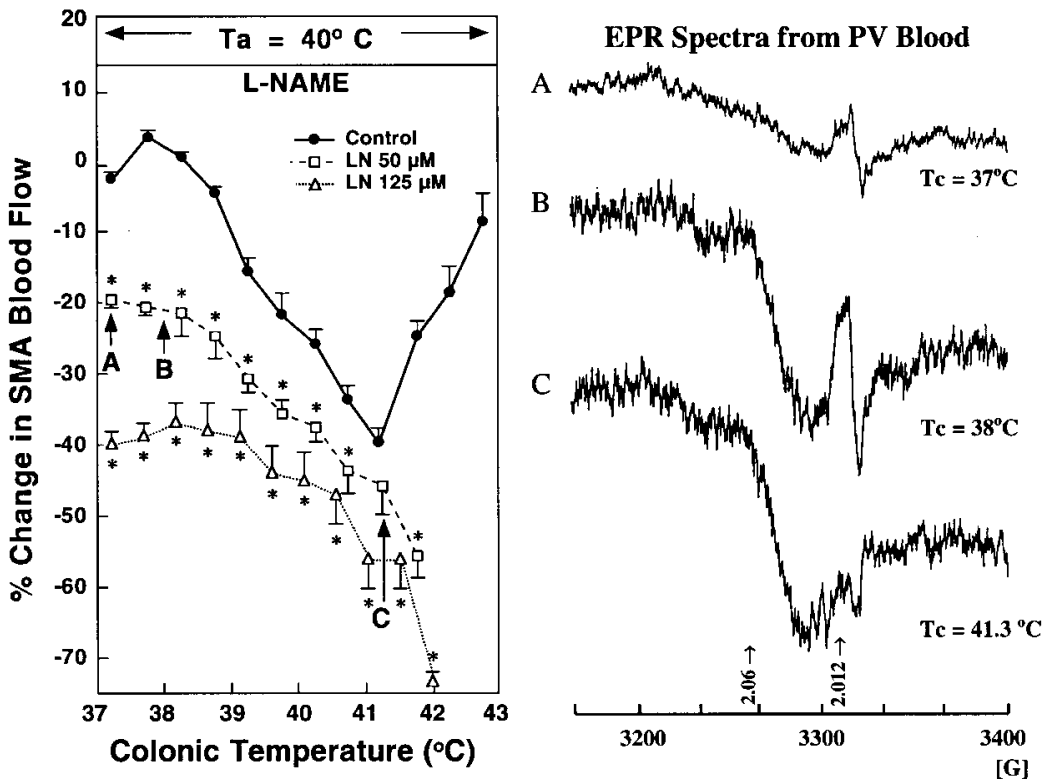

Fig. 5. Higher doses of L-NAME decreased heat tolerance. Compared with hyperthermic controls, both 50 and $125 \mu \mathrm{M}$ L-NAME ( $n=8 \mathrm{rats} /$ group) significantly reduced $\mathrm{SBF}$ and increased semiquinone radical and ceruloplasmin formation ( $A$ vs. $B$, respectively). Note that EPR spectra collected at 38 and $41.3^{\circ} \mathrm{C}$ show only evidence of semiquinone radical and ceruloplasmin, consistent with increased metal activation and cellular oxidative stress with NOS blockade. In addition, both 50 and $125 \mu \mathrm{M}$ L-NAME completely blocked the rise in heme--NO levels $(C)$ and eliminated the hyperthermiarelated splanchnic dilation. EPR spectra collected from animals treated with 50 and $125 \mu \mathrm{M}$ L-NAME were similar; therefore, spectra from $50 \mu \mathrm{M}$-treated animals are presented. *Significantly different from control, $P<$ 0.05 . 
Fig. 6. The iNOS antagonist aminoguanidine slows heme--NO and preserves splanchnic constriction. Compared with hyperthermic controls, aminoguanidine $(25 \mu \mathrm{M} ; n=8)$ slowed the rate of decline in SBF and significantly elevated the $\mathrm{T}_{\mathrm{c}}$ at which EPR-detectable heme$\cdot \mathrm{NO}$ and rising SBF were observed (from $41.3 \pm 0.2$ to $42.7 \pm 0.2^{\circ} \mathrm{C}$ ), compare Fig. $6, B$ and $C$, with Fig. 2, $B$ and $C$. Aminoguanidine treatment also appeared to increase ceruloplasmin and semiquinone radical levels. The net effect of $25 \mu \mathrm{M}$ aminoguanidine treatment was a decreased rate of heme--NO accumulation and prolonged splanchnic constriction but an increase in biomarkers of cellular oxidative stress. Treatment with $50 \mu \mathrm{M}$ aminoguanidine $(n=$ 8) had little effect on splanchnic radical production or SBF but significantly reduced heat tolerance. EPR spectra collected from animals treated with 25 and $50 \mu \mathrm{M}$ aminoguanidine were similar; therefore, spectra from $25 \mu \mathrm{M}$ treated animals are presented. *Significantly different from control, $P<0.05$.

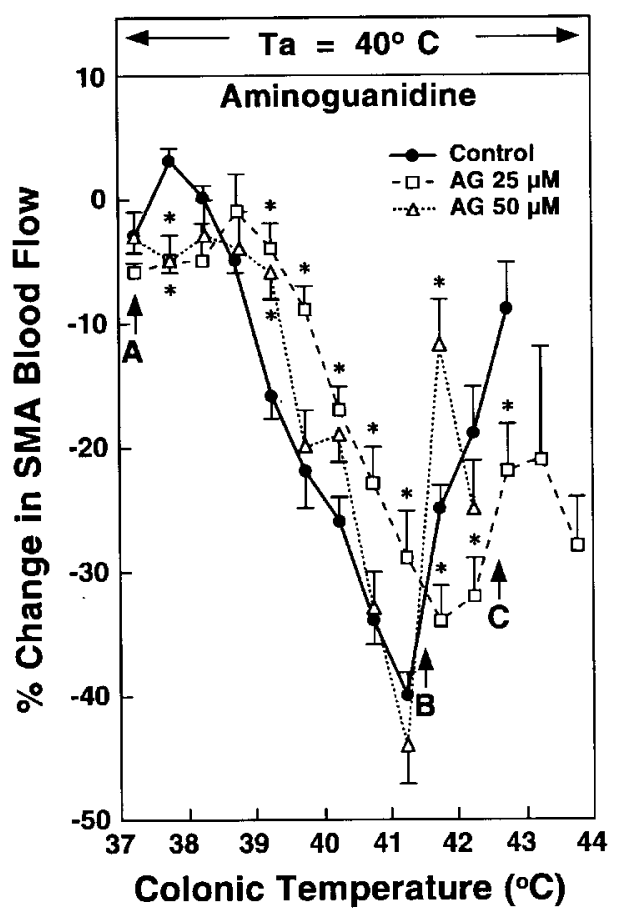

EPR Spectra from PV Blood

A

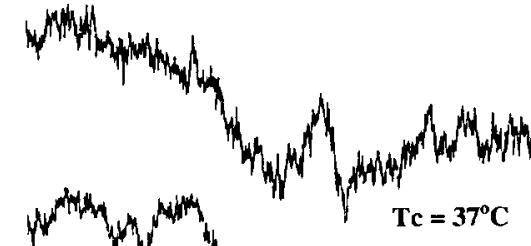

C

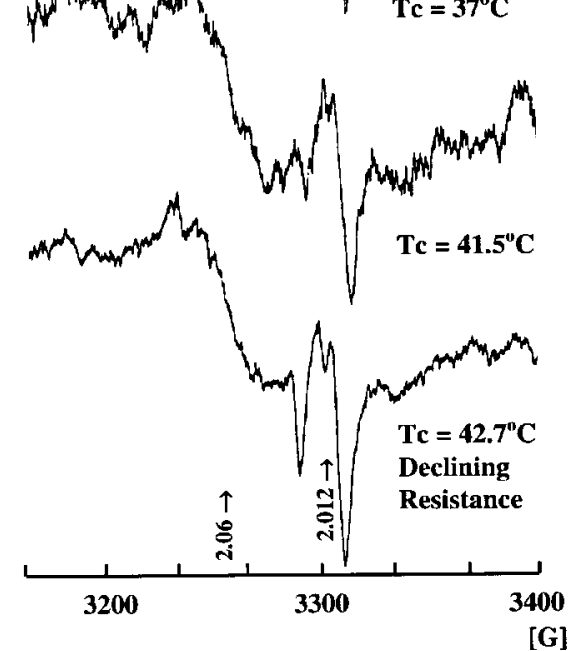

increased the $\mathrm{T}_{c}$ at which heme--NO accumulation and splanchnic dilation were observed $\left(\mathrm{T}_{\mathrm{c}}>42.5\right.$ vs. $41.5^{\circ} \mathrm{C}$ for controls, $P<0.05$ ). Indeed, the vascular radical profile from allopurinol-treated animals and the magnitude of thermal stress required for radical generation were similar to those of animals treated with PEG-SOD (compare Figs. 9 and 7). However, there is a notable absence of EPR-detectable ceruloplasmin with allopurinol treatment (Fig. 9, $A-D$ ).

Allopurinol did not alter the magnitude of change in resistance or SBF (Fig. 9 and Table 1) but shifted the SBF curve rightward, significantly slowing the rate of rise in resistance and the rate of decline in SBF (Fig. 9). On splanchnic dilation, SBF increased to $+20 \pm 4 \%$ above euthermic baseline. Allopurinol also increased peak HR, MAP (Fig. 8), and thermal load (Table 1). HR was maintained at or near peak levels until termination of an experiment (Fig. 8).

\section{Portal Endotoxin}

Portal venous blood collected before heat exposure tested positive for gram-negative bacterial endotoxins at a concentration of $28 \pm 7 \mathrm{pg} / \mathrm{ml}$ (Fig. 10). Arterial blood tested negative for endotoxin (data not shown), suggesting that the liver clears endotoxins under these conditions. Heat stress alone and heat stress plus saline treatment significantly increased portal endotoxin
Fig. 7. PEG-SOD preserves SBF and increases heat tolerance. Left: compared with hyperthermic controls, PEG-SOD (10 and $30 \mathrm{mg} / \mathrm{kg} ; n=8 \mathrm{rats} /$ group) significantly preserved SBF. At a dose of $30 \mathrm{mg} / \mathrm{kg}$, SBF was not reduced below euthermic control levels by heat stress. PEG-SOD also significantly increased the $T_{c}$ at which heme--NO accumulation and rising SBF were observed (from $41.3 \pm 0.2$ to $42.5 \pm 0.2^{\circ} \mathrm{C}$ ), compare Fig. $7, B$ and $C$, with Fig. $2, B$ and $C$. On splanchnic dilation, SMA blood flow increased to $+44 \pm 8 \%$ of control. In addition to preserving blood flow to splanchnic tissues, PEG-SOD markedly decreased semiquinone radical and ceruloplasmin accumulation, suggesting that metal activation and cellular oxidative stress were lowered in this group. EPR spectra collected from animals treated with 10 and $30 \mathrm{mg} / \mathrm{kg}$ PEG-SOD were similar; therefore, spectra from $10 \mathrm{mg} / \mathrm{kg}$-treated animals are presented. *Significantly different from control, $P<0.05$.
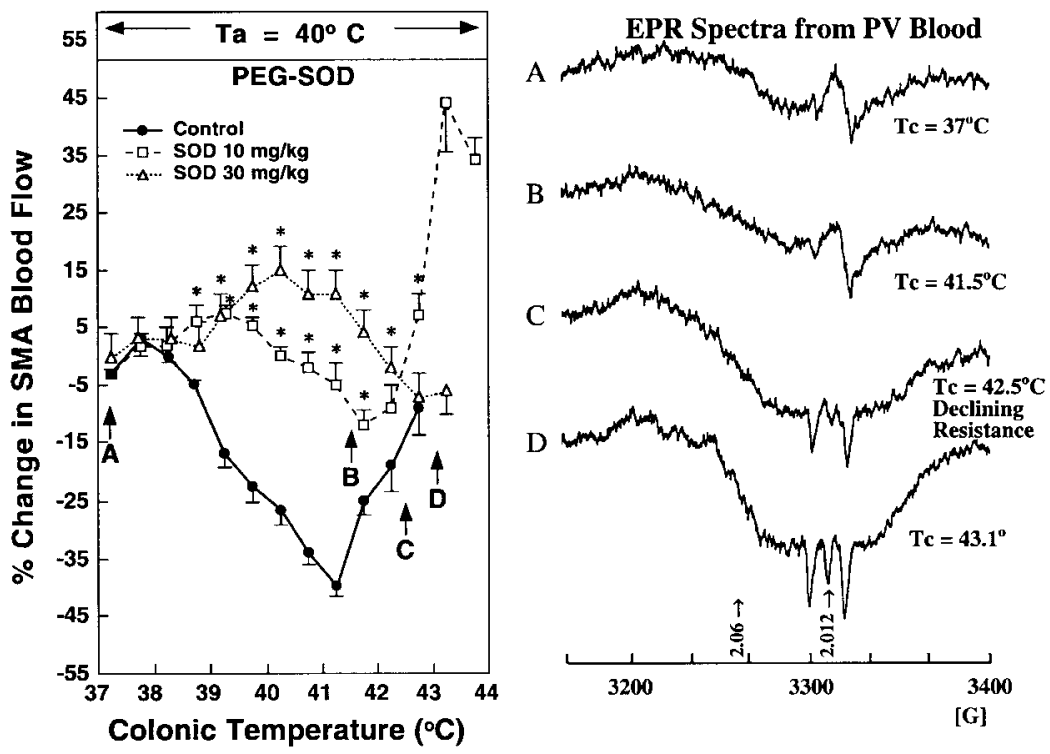

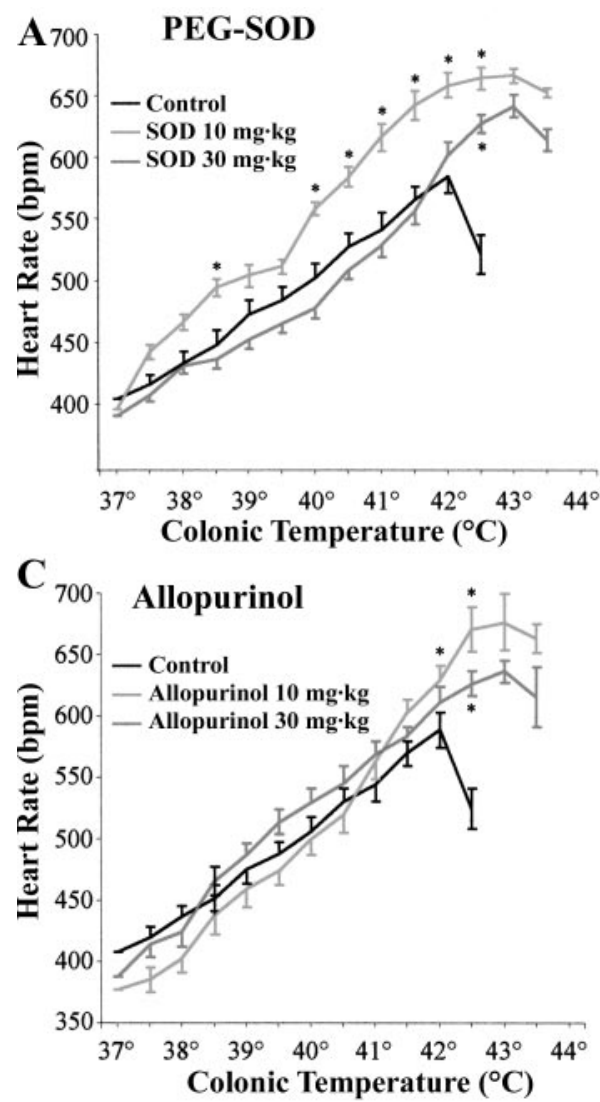
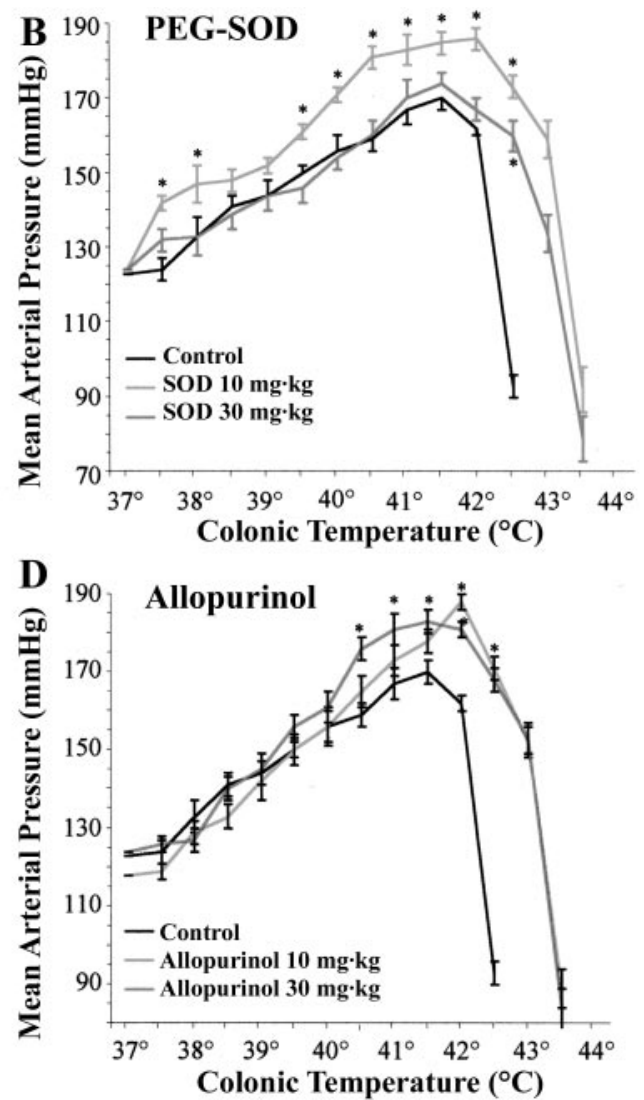

Fig. 8. SOD appears to be involved in $\mathrm{HR}$ and MAP responses during heat stress. Compared with hyperthermic controls, PEG-SOD ( $A$ and $B$ ) and the xanthine oxidase inhibitor allopurinol $(C$ and $D$ ) dose dependently increased the peak HR ( $A$ and $C$ ) achieved during heat stress and significantly increased heat tolerance. Allopurinol also dose dependently increased peak MAP $(D)$ above controls, whereas only the higher concentration of PEG-SOD (30 $\mathrm{mg} / \mathrm{kg}$ ) elevated peak MAP $(B)$ above control. Rats received injections $(10 \mu \mathrm{l} /$ $100 \mathrm{~g}$ body wt iv) at time 0 (beginning of heat exposure) and at 15-min intervals until termination. *Significantly different from control, $P<0.05$. concentration to $59 \pm 7$ and $62 \pm 4 \mathrm{pg} / \mathrm{ml}$, respectively $(P<0.05)$ (Fig. 10). Arterial blood tested negative for endotoxin, suggesting that the liver capacity to clear endotoxins remains intact at $\mathrm{T}_{c}$ of $41.5^{\circ} \mathrm{C}$. Compared with hyperthermic controls, neither PEG-SOD (58 \pm 5 $\mathrm{pg} / \mathrm{ml})$, aminoguanidine $(60 \pm 5 \mathrm{pg} / \mathrm{ml})$, nor L-arginine $(59 \pm 7 \mathrm{pg} / \mathrm{ml})$ treatments altered $41.5^{\circ} \mathrm{C}$ portal endotoxin concentration, whereas L-NAME $(78 \pm 4 \mathrm{pg} / \mathrm{ml})$ significantly increased portal endotoxin levels. Only allopurinol treatment significantly reduced $41.5^{\circ} \mathrm{C}$ endotoxin levels (29 $\pm 8 \mathrm{pg} / \mathrm{ml}, P<0.05)$ (Fig. 10).

\section{DISCUSSION}

The purpose of the present study was to test the hypotheses that splanchnic oxidant generation is an

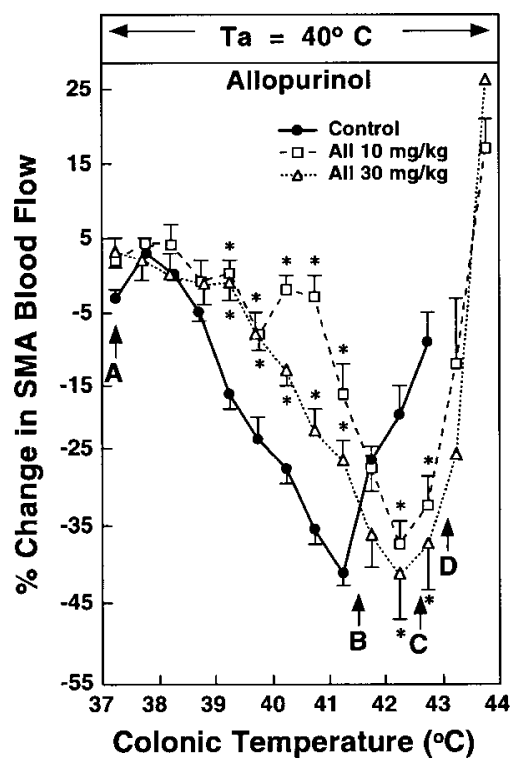

A

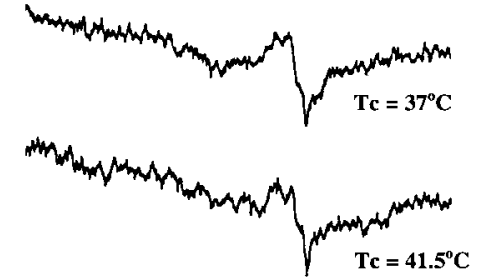

C

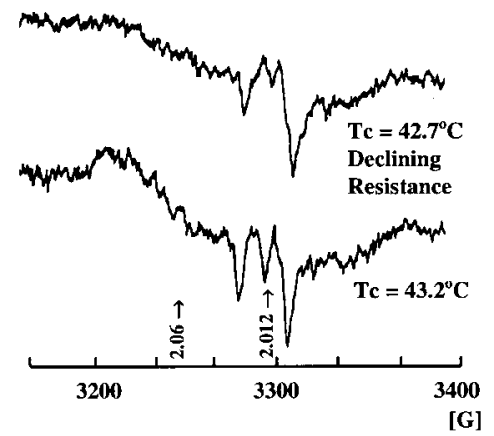

Fig. 9. Allopurinol (All) preserves splanchnic constriction and increases heat tolerance. Left: allopurinol (10 and $30 \mathrm{mg} / \mathrm{kg}$ ) shifted the SBF curves rightward, indicating that it slowed the rate of decline in SBF. In addition, allopurinol treatment decreased semiquinone radical and ceruloplasmin formation, suggesting that metal activation and oxidative stress were lowered in this group. Allopurinol also significantly increased the $\mathrm{T}_{\mathrm{c}}$ at which heme--NO accumulation and splanchnic dilation were observed (from $41.3 \pm 0.2$ to $42.7 \pm$ $0.2^{\circ} \mathrm{C}$ ), compare Fig. $9, B$ and $C$, with Fig. $2, B$ and $C$. On splanchnic dilation, blood flow rose to $+20 \pm 4 \%$ above euthermic control. EPR spectra collected from animals treated with 10 and $30 \mathrm{mg} / \mathrm{kg}$ allopurinol were similar; therefore, spectra from $10 \mathrm{mg} / \mathrm{kg}$-treated animals are presented. *Significantly different from control, $P<0.05$. 


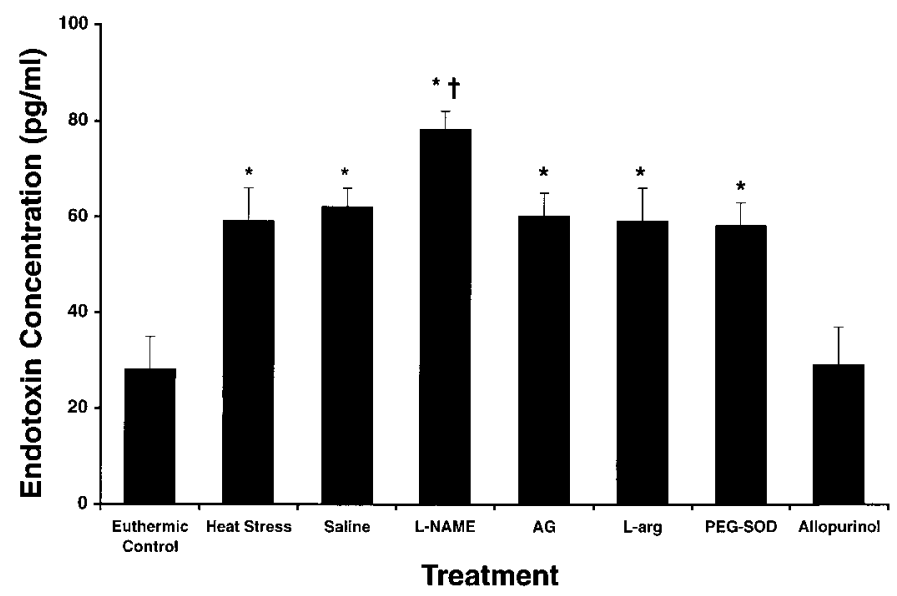

Fig. 10. Allopurinol reduces splanchnic endotoxemia. Portal venous blood was collected from heat-stressed rats at 37.0 and at $41.5^{\circ} \mathrm{C}$ and assayed for endotoxin concentration, as described in MATERIALS AND METHODS. Values (in $\mathrm{pg} / \mathrm{ml}$ ) are expressed as means \pm SD for 4 rats/treatment group. Compared with hyperthermic control animals, L-NAME significantly increased portal endotoxin concentration, whereas only allopurinol treatment was successful at blocking the heat-induced rise in splanchnic endotoxemia levels. * Significantly different from control, $P>0.05$. $\uparrow$ Significantly different from control, $P>0.01$.

important determinant of heat tolerance and that $\cdot \mathrm{NO}$ is involved in splanchnic vascular dysfunction with heat stroke. The major results of the present experiments support these proposals, suggesting that environmental heat stress can stimulate oxidase production of ROS that contribute to metal activation and circulatory and intestinal barrier dysfunction. In addition, the present data demonstrate that intact NOS activity is required for normal heat tolerance, whereas overproduction of 'NO may be responsible for the nonprogrammed loss of splanchnic resistance that precedes heat stroke. We speculate that cellular hypoxia and derangements in intracellular $\mathrm{Ca}^{2+}$ control may be central to the observed increase in ROS and $\cdot \mathrm{NO}$ production (Fig. 1).

\section{EPR Results}

EPR data from the present study demonstrate that environmental heat stress can increase circulating ceruloplasmin levels and stimulate splanchnic semiquinone radical production. Ceruloplasmin is an acute phase protein synthesized by the liver that exhibits robust ferroxidase activity, oxidizing loosely bound transition metals and decreasing their participation in cellular redox chemistry $(24,29)$. The involvement of catalytic metals in oxidant generation and cellular injury is a well-documented phenomenon (33). Accordingly, ceruloplasmin is viewed as a potent antioxidant protein. Hyperthermia-induced elevations in circulating ceruloplasmin and semiquinone radical levels suggest that metal-catalyzed oxidative stress may contribute to heat stress pathology. We speculate that hepatic tissues (46) and vascular endothelial cells (9) may be sources of catalytic metals under these conditions.

Mechanisms by which hyperthermia causes metal activation are unclear, but both $\mathrm{O}_{2}^{-} \cdot(9)$ and $\cdot \mathrm{NO}(38)$ can reduce protein-bound metals, promoting their participation in redox chemistry. While the current results suggest that production of both $\mathrm{O}_{2}^{-} \cdot$ and $\cdot \mathrm{NO}$ are stimulated by heat stress, the fact that PEG-SOD and allopurinol treatments lowered ceruloplasmin concentrations, whereas L-NAME increased ceruloplasmin, suggests that $\mathrm{O}_{2}^{-}$. may be the effector molecule that activates transition metals during hyperthermia. It is unlikely, given the large size of the PEG-SOD complex and the relatively short duration of these experiments, that PEG-SOD could be impacting mitochondrial $\mathrm{O}_{2}^{-}$. production. Rather, these results imply that extramitochondrial sources of $\mathrm{O}_{2}^{-} \cdot$, such as cellular oxidases, may be involved. Data from experiments using allopurinol as an intervention support this conclusion. Collectively, we interpret these results as evidence that heat stress stimulates oxidase production of $\mathrm{O}_{2}^{-}$. and $\mathrm{H}_{2} \mathrm{O}_{2}$, leading to transition metal activation within splanchnic tissues. Adaptive responses include hepatic release of ceruloplasmin and local $\cdot \mathrm{NO}$ production.

The present study strongly suggests that constituitive synthesis of $\cdot \mathrm{NO}$ is essential for successful adaptation to acute heat stress, whereas NOS II activation may underlie hyperthermia-induced splanchnic dilation. Antagonizing NOS with L-NAME dose dependently lowered heme- $\mathrm{NO}$ accumulation and SBF, increased semiquinone radical levels, and lowered heat tolerance. In contrast, aminoguanidine treatment slowed but did not eliminate heme--NO accumulation, significantly delayed splanchnic dilation, and improved heat tolerance more than any other intervention. On the basis of previously cited in vivo work (6, 16), we speculate that aminoguanidine antagonized inducible but not constituitive $\cdot \mathrm{NO}$ synthesis in these experiments. We interpret these results as evidence that NOS II activation contributes to hyperthermiarelated splanchnic dilation. Alternatively, because aminoguanidine also inhibits diamine oxidase, these results may indicate that antagonizing amine metabolism during heat stress lowers NOS activation. However, while the precise mechanism of action for aminoguanidine remains unclear, these results suggest that constituitive NO production protects normal heat tolerance, whereas NOS II activation may compromise thermoregulatory processes by lowering peripheral resistance.

The present work was not designed to evaluate mechanisms underlying the protective effects of $\cdot \mathrm{NO}$, but low flux $\cdot \mathrm{NO}$ production has been shown to enhance cellular antioxidant capacity, acting as a primary antioxidant (51) and as a chain-breaking antioxidant (21, $25,50,51)$. During heat stress, $\cdot \mathrm{NO}$ may act to buffer the rise in intracellular ROS levels and subsequent generation of lipid peroxides. In addition, $\cdot \mathrm{NO}$ opposes splanchnic vasoconstrictor activity, thereby preserving SBF and potentially reducing tissue hypoxia and acidosis (17). Local hypoxia elicits vasoconstriction followed by relaxation in mesenteric arterioles (31), and acidosis is a key predictor of negative clinical outcomes from heat illness (35). Moreover, $\cdot \mathrm{NO}$ inhibits platelet aggregation (34), neutrophil adherence to activated 
endothelial cells (30), and leukocyte NADPH oxidase activity (5), all of which may contribute to heat stress pathology.

Interestingly, in addition to antagonizing NOS II, aminoguanidine also slows vasoactive amine turnover by antagonizing enzymes that metabolize polyamines (15). Cellular oxidases involved in amine metabolism directly produce both $\mathrm{O}_{2}^{-} \cdot$ and $\mathrm{H}_{2} \mathrm{O}_{2}$ as byproducts; therefore, this raises the possibility that aminoguanidine may have exerted beneficial effects by simultaneously antagonizing NOS II and by decreasing cellular oxidase activity.

\section{Cardiovascular Results}

The present data suggest that $\cdot \mathrm{NO}$ is directly involved in hyperthermia-induced splanchnic dilation. However, experiments using PEG-SOD and allopurinol as antioxidant interventions also support a role for ROS in this outcome. Dismuting $\mathrm{O}_{2}^{-} \cdot$ to $\mathrm{H}_{2} \mathrm{O}_{2}$ with PEG-SOD lowered splanchnic constriction more than any other intervention. EPR evidence suggests that the profound decrease in splanchnic resistance occurred independent of increased $\mathrm{NO}$ bioavailability. Conversely, reducing both $\mathrm{O}_{2}^{-} \cdot$ and $\mathrm{H}_{2} \mathrm{O}_{2}$ production with allopurinol slowed the rate of constriction but did not alter the magnitude of reduction in SBF. These results establish that $\mathrm{O}_{2}^{-} \cdot$ is a powerful heat-induced constricting agent within the splanchnic circulation $(39,42)$ and suggest that $\mathrm{H}_{2} \mathrm{O}_{2}$ may have synergized with $\cdot \mathrm{NO}$ in producing splanchnic dilation.

Support for this interpretation is provided by previous work from Rubanyi et al. (40) and Vanhoutte et al. (49), who reported that $\mathrm{H}_{2} \mathrm{O}_{2}$ can produce vasodilation by acting directly on vascular smooth muscle (40) or by stimulating guanylate cyclase activity and depolarizing $\mathrm{K}^{+}$channels (49). Moreover, like $\cdot \mathrm{NO}, \mathrm{H}_{2} \mathrm{O}_{2}$ can readily cross biological membranes; therefore, we speculate that both ROS and reactive nitrogen species may contribute to local circulatory dysfunction during heat stress.

\section{Endotoxin Results}

Results from the present study establish that severe heat stress can produce splanchnic endotoxemia. However, hepatic reticuloendothelial cell function remains intact up to $41.5^{\circ} \mathrm{C}$ because endotoxins were not detected in the systemic circulation. These effects were eliminated with allopurinol treatment and exacerbated with L-NAME. This suggests that ROS produced by xanthine oxidase may be responsible for the observed rise in splanchnic endotoxin levels, whereas $\cdot \mathrm{NO}$ may be a critical molecule that protects intestinal barrier function and/or contributes to reticuloendothelial cell endotoxin removal.

The heat sensitivity and physiological significance of xanthine oxidase was first demonstrated by Skibba et al. $(44,45)$, who reported that stimulation of hepatic xanthine oxidase activity produced metal-catalyzed oxidative injury in the hyperthermic liver. Subsequent works by Tan et al. (47) and Terada et al. (48) have shown that an ischemic insult to the intestine and liver can stimulate cellular export of xanthine oxidase. Once in the vascular compartment, xanthine oxidase can be bound by endothelial cell glycosaminoglycans (47), localizing the enzyme next to endothelial cell surfaces.

In the current work, heat stress reduced SBF by $\sim 40 \%$ as $\mathrm{T}_{\mathrm{c}}$ rose from 37 to $41.5^{\circ} \mathrm{C}$. We (17) have previously shown that heat stress of this magnitude produces significant cellular hypoxia in the liver and intestine. Hypoxia can stimulate conversion of xanthine dehydrogenase to xanthine oxidase and increase its cellular export (23). Although the current project did not directly measure xanthine oxidase activity, our data suggest that the combined effects of heat and cellular hypoxia may have stimulated cellular xanthine oxidase activity, leading to intestinal injury and splanchnic endotoxemia.

The role of endotoxins in heat illness remains to be established. The current view of the involvement of splanchnic organs in the pathogenesis of heat stroke is that ischemic and/or thermal stresses can damage the intestinal wall, allowing endotoxins to escape the intestinal lumen and enter the portal circulation $(1,13)$. Thermal injury to the liver would then allow endotoxins to spill over into the systemic circulation, stimulating a cascade of events similar to systemic inflammatory response syndrome. However, it generally requires much higher $\mathrm{T}_{c}$ to produce spillover; therefore, the role of endotoxins in the current work remains debatable. However, it is noteworthy that pretreating experimental animals with steroids, antiendotoxin antibodies, or with antibiotics to reduce gut flora reduces heat stress lethality $(3,10-12)$. On the basis of the present work, we suggest that the above-listed interventions may have acted by reducing NOS II activation.

In summary, interventions that increased systemic antioxidant capacity (aminoguanidine, PEG-SOD, or allopurinol) decreased production of radical biomarkers of metal-catalyzed oxidative stress. Agents that reduced NOS II or cellular oxidase activity (aminoguanidine and allopurinol) also significantly improved cardiovascular performance and heat tolerance. The mechanisms responsible for these results could involve decreased cellular ROS production and transition metal activation in combination with reduced flux of $\cdot \mathrm{NO}$.

Additionally, these data establish that intact NOS activity is required for normal heat tolerance, whereas overproduction of $\cdot \mathrm{NO}$ and $\mathrm{H}_{2} \mathrm{O}_{2}$ may be responsible for local circulatory dysfunction with heat stroke. Xanthine oxidase may be a critical heat-sensitive cellular oxidase that contributes to intestinal barrier dysfunction and splanchnic dilation. On the basis of these data, we conclude that splanchnic oxidant generation is an important determinant of heat tolerance and that -NO is involved in vascular dysfunction with heat stroke.

The authors acknowledge the expert secretarial assistance of Joan Seye. 
This work was supported by NIH Grants CA-66081, CA-81090, and AG-12350 (to G. R. Buettner and L. W. Oberley), HL-61389 (to C. V. Gisolfi), and T32 AG-00214 (Interdisciplinary Research Training Program on Aging Fellowship; to D. M. Hall).

\section{REFERENCES}

1. Brock-Utne JG, Gaffin SL, Wells MT, Gathiram P, Sohar E, James MF, Morrell DF, and Norman RJ. Endotoxaemia in exhausted runners following a long distance race. $S$ Afr Med $J$ 73: 533-536, 1988.

2. Buettner GR, Scott BD, Kerber RE, and Mugge A. Free radicals from plastic syringes. Free Radic Biol Med 11: 69-70, 1991.

3. Bynum G, Brown J, DuBose D, Marsili M, Leav I, Pristole TG, Hamlet M, Lemaire M, and Caleb B. Increased survival in experimental dog heatstroke after reduction of gut flora. Aviat Space Environ Med 50: 816-819, 1979.

4. Cantilena LR, Smith RP, Frasur S, Kruszyna H, Kruszyna $\mathbf{R}$, and Wilcox DE. Nitric oxide hemoglobin in patients receiving nitroglycerin as detected by electron paramagnetic resonance spectroscopy. J Lab Clin Med 120: 902-907, 1992.

5. Clancy RM, Leszczynska-Piziak J, and Abramson SB. Nitric oxide, an endothelial cell relaxation factor, inhibits neutrophil superoxide anion production via a direct action on the NADPH oxidase. J Clin Invest 90: 1116-1121, 1992.

6. Corbett JA, Tilton RG, Chang K, Hasan KS, Ido Y, Wang JL, Sweetland MA, Lancaster JR Jr, Williamson JR, and McDaniel ML. Aminoguanidine, a novel inhibitor of nitric oxide formation, prevents diabetic vascular dysfunction. Diabetes 41: $552-556,1992$

7. D'Oleire F, Schmitt CL, Robins HI, Cohen JD, and Spriggs D. Cytokine induction in humans by 41.8 degrees $\mathrm{C}$ whole-body hyperthermia. J Natl Cancer Inst 85: 833-834, 1993.

8. Friberger P, Knos M, and Mellstam L. Endotoxins and Their Detection with the Limulus Amebocyte Lysate Test. New York: Lea \& Febiger, 1982, p. 195-206.

9. Gannon DE, Varani J, Phan SH, Ward JH, Kaplan J, Till GO, Simon R, Ryan US, and Ward PA. Source of iron in neutrophil-mediated killing of endothelial cells. Lab Invest 57: 37-44, 1987.

10. Gathiram P, Wells MT, Brock-Utne JG, and Gaffin SL. Antilipopolysaccharide improves survival in primates subjected to heat stroke. Circ Shock 23: 157-164, 1987.

11. Gathiram P, Wells MT, Brock-Utne JG, and Gaffin SL. Prophylactic corticosteroid increases survival in experimental heat stroke in primates. Aviat Space Environ Med 59: 352-355, 1988.

12. Gathiram P, Wells MT, Brock-Utne JG, Wessels BC, and Gaffin SL. Oral administered nonabsorbable antibiotics prevent endotoxemia in primates following intestinal ischemia. J Surg Res 45: 187-193, 1988 .

13. Gathiram P, Wells MT, Raidoo D, Brock-Utne JG, and Gaffin SL. Portal and systemic plasma lipopolysaccharide concentrations in heat-stressed primates. Circ Shock 25: 223-230, 1988.

14. Gisolfi CV, Matthes RD, Kregel KC, and Oppliger R. Splanchnic sympathetic nerve activity and circulating catecholamines in the hyperthermic rat. J Appl Physiol 70: 18211826,1991

15. Griffith OW and Stuehr DJ. Nitric oxide synthases: properties and catalytic mechanism. Annu Rev Physiol 57: 707-736, 1995.

16. Grisham MB, Specian RD, and Zimmerman TE. Effects of nitric oxide synthase inhibition on the pathophysiology observed in a model of chronic granulomatous colitis. J Pharmacol Exp Ther 271: 1114-1121, 1994.

17. Hall DM, Baumgardner KR, Oberley TD, and Gisolfi CV. Splanchnic tissues undergo hypoxic stress during whole body hyperthermia. Am J Physiol Gastrointest Liver Physiol 276: G1195-G1203, 1999.

18. Hall DM, Buettner GR, Matthes RD, and Gisolfi CV. Hyperthermia stimulates nitric oxide formation: electron paramagnetic resonance detection of NO-Heme in blood. J Appl Physiol 77: 548-553, 1994.
19. Hall DM, Oberley TD, Moseley PM, Buettner GR, Oberley LW, Weindruch R, and Kregel KC. Caloric restriction improves thermotolerance and reduces hyperthermia-induced cellular damage in old rats. FASEB $J$ 14: 78-86, 2000.

20. Hartley CJ and Cole JS. An ultrasonic pulsed Doppler system for measuring blood flow in small vessels. J Appl Physiol 37: 626-629, 1974.

21. Hogg N, Kalyanaraman B, Joseph J, Struck A, and Parthasarathy S. Inhibition of low-density lipoprotein oxidation by nitric oxide. Potential role in atherogenesis. FEBS Lett 334: $170-174,1993$

22. Hubbard RW, Bowers WD, Matthew WT, Curtis FC, Criss REL, Sheldon GM, and Ratteree RW. Rat model of acute heatstroke mortality. J Appl Physiol 42: 809-816, 1977.

23. Jarasch ED, Bruder G, and Heid HW. Significance of xanthine oxidase in capillary endothelial cells. Acta Physiol Scand Suppl 548: 39-46, 1986.

24. Kanner J, Sofer F, Harel S, and Doll L. Antioxidant activity of ceruloplasmin in muscle membrane and in situ lipid peroxidation. J Agric Food Chem 36: 415-417, 1988.

25. Kelley EE, Wagner BA, Buettner GR, and Burns CP. Nitric oxide inhibits iron-induced lipid peroxidation in HL-60 cells. Arch Biochem Biophys 370: 97-104, 1999.

26. Knochel JP. Heat stroke and related heat stress disorders. Disease of the Month 35: 306-377, 1989.

27. Kosaka H. Nitric oxide and hemoglobin interactions in the vasculature. Biochim Biophys Acta 1411: 370-377, 1999.

28. Kregel KC, Wall PT, and Gisolfi CV. Peripheral vascular responses to hyperthermia in the rat. $J$ Appl Physiol 64: 2582$2588,1988$.

29. Krsek-Staples JA and Webster RO. Ceruloplasmin inhibits carbonyl formation in endogenous cell proteins. Free Radic Biol Med 14: 115-125, 1993.

30. Kubes P, Suzuki M, and Granger DN. Nitric oxide: an endogenous modulator of leukocyte adhesion. Proc Natl Acad Sci USA 88: 4651-4655, 1991.

31. Leach RM, Robertson TP, Twort CHC, and Ward JPT. Hypoxic vasoconstriction in rat pulmonary and mesenteric arteries. Am J Physiol Lung Cell Mol Physiol 266: L223-L231, 1994.

32. Merimee TJ, Rabinowtitz D, and Fineberg SE. Arginineinitiated release of human growth hormone. Factors modifying the response in normal man. $N$ Engl $J$ Med 280: 1434-1438, 1969 .

33. Miller DM, Grover TA, Nayini N, and Aust SD. Xanthine oxidase- and iron-dependent lipid peroxidation. Arch Biochem Biophys 301: 1-7, 1993.

34. Moncada S and Higgs A. The L-arginine-nitric oxide pathway. N Engl J Med 329: 2002-2012, 1993.

35. Moseley PL. Mechanisms of heat adaptation: thermotolerance and acclimation. J Lab Clin Med 123: 48-52, 1994.

36. Powers RH, Stadnicka A, Kalbfleish JH, and Skibba JL. Involvement of xanthine oxidase in oxidative stress and iron release during hyperthermic rat liver perfusion. Cancer Res 52: 1699-1703, 1992.

37. Rees DD, Palmer RM, Schultz R, Hodson HF, and Moncada S. Characterization of three inhibitors of endothelial nitric oxide synthase in vitro and in vivo. $B r$ J Pharmacol 101: $746-752,1990$

38. Reif DW and Simmons RD. Nitric oxide mediates iron release from ferritin. Arch Biochem Biophys 283: 537-541, 1990.

39. Rubanyi G. Vascular effects of oxygen-derived free radicals. Free Radic Biol Med 4: 107-120, 1988.

40. Rubanyi GM and Vanhoutte PM. Oxygen-derived free radicals, endothelium, and responsiveness of vascular smooth muscle. Am J Physiol Heart Circ Physiol 250: H815-H821, 1986.

41. Saifer M, Somack R, and Williams LD. Plasma clearance and immunologic properties of long-acting superoxide dismutase prepared using 35,000 to 120,000 dalton polyethylene glycol. Adv Exp Med Biol 366: 377-387, 1994.

42. Saran M, Michel C, and Bors W. Reaction of NO with $\mathrm{O}_{2}^{-}$. Implications for the action of endothelium-derived relaxing factor (EDRF). Free Radic Res 10: 221-226, 1990. 
43. Simon HB. Hyperthermia and heatstroke. Hosp Pract (Off Ed) 29: 65-68, 1994.

44. Skibba JL, Powers RH, Stadnicka A, Cullinane DW, Almagro UA, and Kalbfleisch JH. Oxidative stress as a precursor to the irreversible hepatocellular injury caused by hyperthermia. Int J Hyperthermia 7: 749-761, 1991.

45. Skibba JL, Powers RH, Stadnicka A, and Kalbfleisch JH. The effect of hyperthermia on conversion of rat hepatic xanthine dehydrogenase to xanthine oxidase. Biochem Pharmacol 37: 4592-4595, 1988.

46. Stahl WM. Acute phase protein response to tissue injury. Crit Care Med 15: 545-550, 1987.

47. Tan S, Yokoyama Y, Dickens E, Cash TG, Freeman BA, and Parks DA. Xanthine oxidase activity in the circulation of rats following hemorrhagic shock. Free Radic Biol Med 15: 407414, 1993.

48. Terada LS, Dormish JJ, Shanley PF, Leff JA, Anderson BO, and Repine JE. Circulating xanthine oxidase mediates lung neutrophil sequestration after intestinal ischemia-reperfusion. Am J Physiol Lung Cell Mol Physiol 263: L394-L401, 1992.

49. Vanhoutte PM. Modulation of vascular smooth muscle contraction by the endothelium. Annu Rev Physiol 48: 307-320, 1986.

50. Wink DA, Cook JA, Krishna MC, Hanbauer I, DeGraff W, Gamson J, and Mitchell JB. Nitric oxide protects against alkyl peroxide-mediated cytotoxicity: further insights into the role nitric oxide plays in oxidative stress. Arch Biochem Biophys 319: 402-407, 1995.

51. Wink DA, Hanbauer I, Krishna MC, DeGraff W, Gamson J, and Mitchell JB. Nitric oxide protects against cellular damage and cytotoxicity from reactive oxygen species. Proc Natl Acad Sci USA 90: 9813-9817, 1993.

52. Winterbourne CC. Evidence for the production of hydroxyl radicals from the adriamycin semiquinone and $\mathrm{H}_{2} \mathrm{O}_{2}$. FEBS Lett 136: 89-94, 1981.

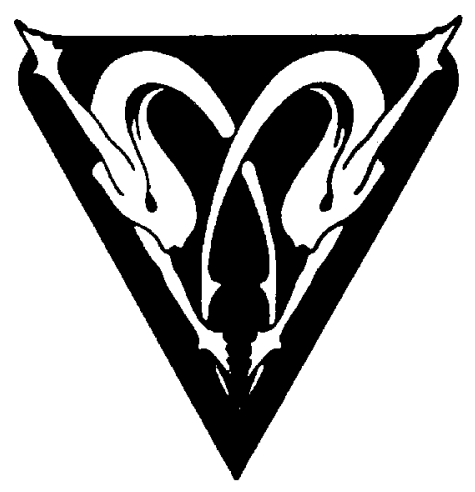

